\title{
A contribuição da fundação tênis e dos valores olímpicos na vida e na formação escolar de ex-participantes do projeto em Santiago/RS
}

The contribution of the tennis foundation and Olympic values in the life and school education of ex project participants in Santiago City/RS/ Brazil

La contribución de la fundación tenis y de los valores olímpicos en la vida y en la formación escolar de ex participantes del proyecto en Santiago/RS/ Brazil

\author{
Angélica Salbego da Rosa ${ }^{\mathrm{I}}$, Lorenzo Iop Laporta ${ }^{\mathrm{II}}$
}

\section{RESUMO}

O tênis de quadra é uma via para a educação, desenvolve valores, estimula a socialização e o respeito. O projeto Fundação Tênis utiliza dos Valores Olímpicos para indivíduos provenientes de comunidades mais necessitadas, oportunizando a mudança de vida através da prática do tênis. Aplicou-se um questionário objetivando avaliar a contribuição da Fundação Tênis e dos Valores Olímpicos na vida e na formação escolar de 17 ex-participantes do projeto em Santiago/RS. Os resultados evidenciaram a importância do professor e a contribuição dos valores olímpicos na vida dos participantes, como, também, as oportunidades de entrada para o mercado de trabalho.

Palavras-chave: Educação; Esporte; Tênis

\section{ABSTRACT}

Outdoor tennis is a way for education, develops values, encourages socialization and respect. The Tennis Foundation project uses the Olympic Values for individuals from the neediest communities, giving them the opportunity to change their lives through the tennis practice. A questionnaire was applied to evaluate the Tennis Foundation contribution and Olympic Values in life and in school education of seventeen (17) ex project participants, in Santiago City/RS/Brazil. Results showed the teacher importance and Olympic Values contribution in the participants' life, as well as the opportunities of access into the job market.

Keywords: Education; Sport; Tennis

\footnotetext{
${ }^{\text {I }}$ Universidade Regional Integrada do Alto Uruguai e das Missões - URI - Santiago, RS, Brasil - Endereço: Avenida Batista Bonoto Sobrinho, 733- São Vicente, Santiago- RS, CEP- 97700000 - e-mail: angelica-salbego@ hotmail.com

${ }^{\text {II } U n i v e r s i d a d e ~ R e g i o n a l ~ I n t e g r a d a ~ d o ~ A l t o ~ U r u g u a i ~ e ~ d a s ~ M i s s o ̃ e s ~-~ U R I ~-~ S a n t i a g o, ~ R S, ~ B r a s i l ~-~ e-m a i l: ~ l o r e n z o l a p o r t a @ ~ h o t m a i l . c o m ~}$
} 


\section{RESUMEN}

El tenis de cuadra es una vía para la educación, desarrolla valores, estimula la socialización y el respeto. El proyecto Fundación Tenis utiliza los Valores Olímpicos para individuos provenientes de comunidades más necesitadas y proporciona oportunidades de cambio de vida a través de la práctica deportiva del tenis. Se aplicó un cuestionario con el objetivo de avaluar la contribución de la Fundación Tenis y de los Valores Olímpicos en la vida y en la formación escolar de 17 ex participantes del proyecto en Santiago/RS. Los resultados evidenciaron la importancia del profesor y el aporte de los valores olímpicos en la vida de los participantes, así como las oportunidades para ingresar al mercado laboral.

Palabras Clave: Educación; Deportes; Tênis

\section{Introdução}

O esporte pode ser um meio de transformar a vida de crianças e adolescentes que se encontram em realidade social precária. Considerado fundamental para o desenvolvimento da criança, desde a brincadeira até a vertente mais formal, oferece ainda ferramentas indispensáveis para uma vida saudável, além de educar os participantes por meio de valores colocados em prática diariamente (PARA O DESENVOLVIMENTO, ONU ESPORTE, 2007). Segundo Daiuto (1983), o esporte é fundamental para o progresso psicológico, social e biológico, pois é um meio de socializar o indivíduo no ambiente no qual está inserido e ajudar na interação com outros indivíduos, através do domínio emocional, confiança em si próprio e diminuição da agressividade.

Dessa forma, as crianças, ao praticarem alguma atividade esportiva, permanecem ligadas a um crescimento psicomotor por intermédio da prática, oportunizando formar cidadãos e transformar suas vidas através do esporte (MARINS; DOS SANTOS; MARQUES, 2014). Já na escola, quando o aluno pratica algum esporte, as habilidades motoras são desenvolvidas, os aspectos sociais e as capacidades físicas são estimuladas, resultando um melhor desempenho pedagógico, além de ter um compromisso com a cidadania e o futuro das crianças e jovens (PINTO; CUNHA, 1998).

Diversos esportes podem ser trabalhados no âmbito escolar. O tênis é um exemplo, pois a criança pode vivenciá-lo com atividades recreativas, trabalhando a socialização, aprendendo a respeitar o seu espaço e o do colega, em busca de uma adequação em que o prazer em jogar possa oferecer benefícios sociais para o lazer (DAIUTO, 1983).

Como dito anteriormente, o Tênis pode ser um aliado no alcance de vários objetivos, apesar de seu lado elitista. Além disso, o tênis possui e estabelece o respeito às regras (fair play), condutas esportivas, desenvolvimento de liderança e competitividade, trabalho em equipe e diversão (ALEXANDER; LUCKMAN, 2001; GRAÇA, 2004). 
Coubertain, considerado o "pai" do Movimento Olímpico, acreditava no esporte para o desenvolvimento social, valor educativo, respeito, caráter e na formação do indivíduo através de uma ação pedagógica na educação, projetos e programas sociais (TODT, 2014). Nesse sentido, a Educação Olímpica pode ser uma ferramenta para oferecer oportunidade e vivências que levam ao crescimento e desenvolvimento humano, baseado em valores atribuídos na prática esportiva e no aprimoramento do indivíduo como um princípio ético e moral seguindo regras e normas. Os objetivos da Educação Olímpica são proporcionar uma educação universal, desenvolvendo e atribuindo mudanças que estão relacionadas ao comportamento do indivíduo com a sociedade (PINTO; RODRIGUES; ENGELMAN, 2009).

O Brasil, referência de Educação Olímpica, possui programas sociais e escolares (TODT, 2015), como por exemplo: o projeto Fundação Tênis nos estados do Rio Grande do Sul e São Paulo; Programa esportivo social - Estação Conhecimento no estado do Espírito Santo; Programa de Esportes em Nível de Ensino Elementar desenvolvido na Universidade Regional Integrada do Alto Uruguai e das MissõesErechim no Rio Grande do Sul.

Nesse contexto, a Fundação Tênis (FT) é uma organização não governamental (ONG) com o objetivo de desenvolver um programa social por meio da Educação Olímpica (MÜLLER, 1986) e do tênis de quadra, levando esse esporte tão elitizado a jovens oriundos de comunidades mais necessitadas e, posteriormente, encaminhando-os para cursos profissionalizantes do Brasil. A FT tem como missão "promover o desenvolvimento de crianças e adolescentes provenientes de comunidades mais necessitadas, dando a oportunidade de, por intermédio da prática sistemática e disciplinada do tênis, reescreverem o seu projeto de vida"1.

O projeto atende 1.071 crianças no Brasil ${ }^{2}$, moradoras das cidades de Porto Alegre/RS, Igrejinha/RS, Sapiranga/RS, Santiago/RS e São Paulo/SP. Em Santiago/RS, a Fundação Tênis trabalha em dois núcleos que atendem 178 crianças moradoras dos bairros carentes e com problemas familiares.

Assim, além dos objetivos citados anteriormente, o projeto possui a missão de encaminhar seus alunos para cursos profissionalizantes e/ou prepará-los para o mercado de trabalho. A ONG oferece os cursos em turno oposto escolar e de forma gratuita para aqueles alunos que já estão no último ano do Ensino Fundamental ou que tenham 15 anos completos, esclarecendo dúvidas e auxiliando a uma escolha profissional, ou até mesmo chances de ingressarem em vagas no mercado de trabalho.

A FT segue princípios metodológicos norteadores do projeto, em que o planejamento das aulas é dividido em três etapas: Início ou Pré-Aula, Metodologia da Aula e o Pós Aula. Assim sendo, o

${ }^{1}$ Dados retirados do site www.fundacaotenis.org.br, acesso em junho de 2017.

${ }^{2}$ Dados retirados da revista Na Rede, publicada em Jun 2016, n²7. 
planejamento está de acordo com a missão, visão e os valores olímpicos do projeto, estabelecendo objetivos e definindo o melhor caminho para atingi-los na prática, evitando "queimar" etapas para não comprometer todo o princípio metodológico. Além disso, o respeito, excelência e amizade são os Valores Olímpicos norteadores das aulas para a educação e transformação indireta de vidas (COUBERTIN, 2000). A excelência diária; respeito com os colegas, professores e materiais; o fair play (jogo limpo - respeito às regras do jogo); e máxima dedicação e esforço para aprender (TAVARES, 2003) são requisitos obrigatórios de cada integrante do projeto.

Portanto, o estudo teve como objetivo investigar a contribuição da Fundação Tênis e dos Valores Olímpicos na vida e na formação escolar de Ex-participantes do Projeto em Santiago/RS, mostrando as possibilidades que o tênis e os valores da Educação Olímpica proporcionaram a esses indivíduos.

\section{Metodologia}

O caminho metodológico é caracterizado, conforme Prodanov e De Freitas (2013), em uma pesquisa de campo quanto aos procedimentos, pois através da criação e aplicação de um questionário procuramos descobrir informações como a contribuição do projeto, das aulas, dos valores olímpicos na vida dos ex-participantes do projeto, entre outros, fornecendo conhecimentos para aplicação prática e solução de problemas no que diz respeito à contribuição da Fundação Tênis e dos Valores Olímpicos na vida e na Formação Escolar de Ex-Participantes do Projeto em Santiago/RS; Descritiva do ponto de vista de seus objetivos descreverem as características dessa população através da aplicação de questionários, proporcionando informações a respeito do assunto investigado. Do ponto de vista da abordagem do problema, a pesquisa será qualitativa e quantitativa dos dados (FLICK, 2008; PRODANOV; DE FREITAS, 2013), de modo que o investigador retrate o maior número possível de elementos existentes na realidade apresentada pelo Projeto FT e pelos alunos participantes.

\subsection{Locais da Pesquisa e Participantes}

A pesquisa foi realizada especificamente nos núcleos do Projeto Fundação Tênis localizados na cidade de Santiago/RS. A amostra contou com aproximadamente 17 jovens que foram selecionados por serem ex-alunos que participaram do Projeto FT, ou por serem alunos evadidos (que já concluíram o ensino fundamental), ou também por aqueles que por algum motivo não fazem mais parte do projeto e 
que estão inseridos em cursos profissionalizantes e no mercado de trabalho. Dessa forma, os critérios de inclusão são apresentados na sequência:

\subsection{Instrumentos}

O questionário foi composto por 6 perguntas fechadas e 3 perguntas abertas. Segundo Cervo e Bervian (2002), perguntas fechadas apresentam alternativas limitadas, oferecendo ao entrevistado todas as alternativas de respostas, já as perguntas abertas são caracterizadas por serem perguntas livres, nas quais o entrevistado escreve sua opinião sobre as perguntas propostas, sem alternativas para marcar. A aplicação do questionário foi realizada no contato direto, em que o pesquisador aplicou ao entrevistado, consistindo em uma relação pesquisador-sujeito.

\subsection{Considerações Éticas}

Todos os dados foram mantidos arquivados e mantidos em sigilo na coordenação do curso de Educação Física da URI Campus Santiago, sendo que as perguntas realizadas na pesquisa foram claras e objetivas, de modo que o indivíduo entrevistado, se caso ficasse desconfortável com qualquer pergunta, pudesse optar por não respondê-la ou ainda não terminar o preenchimento do mesmo, pedindo auxílio ou esclarecimento ao responsável pela entrevista. O Referente trabalho passou pelo protocolo do Comité de Ética da URI ( ${ }^{\circ}$ 76796917. 7. 0000. 5353).

\section{Análise de Dados}

A análise de dados constituiu em duas etapas: a primeira de uma análise descritiva dos dados com análise de frequência e de médias para avaliar quantitativamente os dados, fornecendo ao entrevistado respostas livres, expondo sua opinião através das perguntas relacionadas com o tema da pesquisa (CERVO; BERVIAN, 2002). Já, a segunda parte utilizou da Análise de conteúdo para analisar qualitativamente, descrever o conteúdo e, a partir disso, comparar e fazer inferência com a literatura existente. 


\section{Resultados}

A pesquisa obteve ao total 17 questionários respondidos por ex-alunos do Projeto FT. Dentre as características da amostra, a maioria caracterizou-se por ter idade entre 15 a 25 anos e morar perto das escolas onde encontravam-se os núcleos do Projeto da Fundação Tênis, através dos questionários evidenciaram os resultados:

Figura 1: Pergunta 1 - O que fez você entrar no projeto?

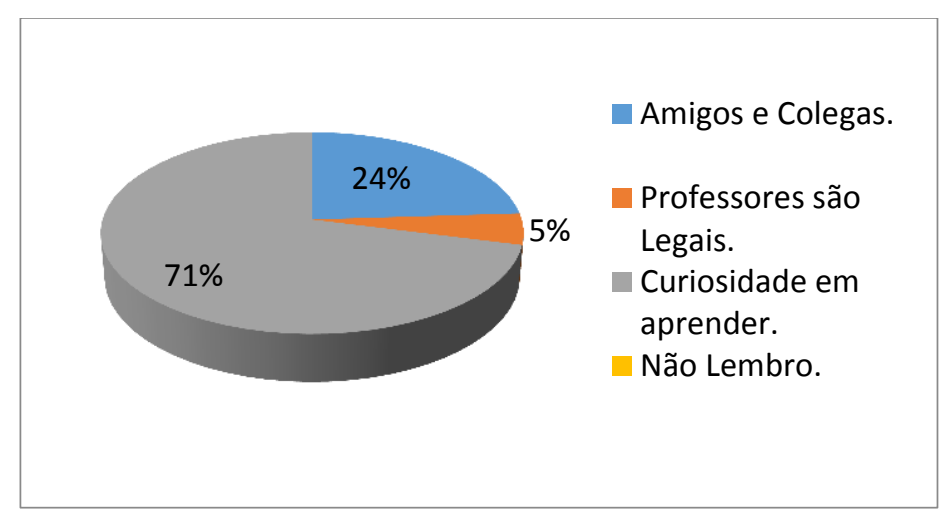

Fonte: elaborados pelos autores

Através do gráfico, podemos observar que $71 \%$ dos alunos entraram no projeto por curiosidade em aprender a jogar tênis, por ser um esporte novo na escola e pouco praticado na cidade, os alunos se adaptaram com o jogo e conheceram a modalidade através das aulas praticadas na sua escola. 24\% responderam que entraram no projeto pelos seus amigos e colegas da escola, os quais passaram informações positivas sobre as aulas de tênis, como também passaram a socializar mais durante as aulas com os mesmos e $5 \%$ porque os professores eram legais, transmitiam conhecimentos, aplicando na prática e desenvolvendo valores para condutas esportivas e possuíam relações de amizades entre todos. Podemos destacar que a maioria dos entrevistados relatam que o tênis serviu como um esporte diferente, nunca praticado na escola e por ser bastante prazeroso para os alunos, o que é um ponto positivo para o projeto, pois despertou interesse nos alunos em praticar e motivar para a aprendizagem, do mesmo modo interagindo na socialização com o grupo no qual se inseriram. 
Figura 2: Pergunta 2 - Quantos anos você frequentou o projeto?

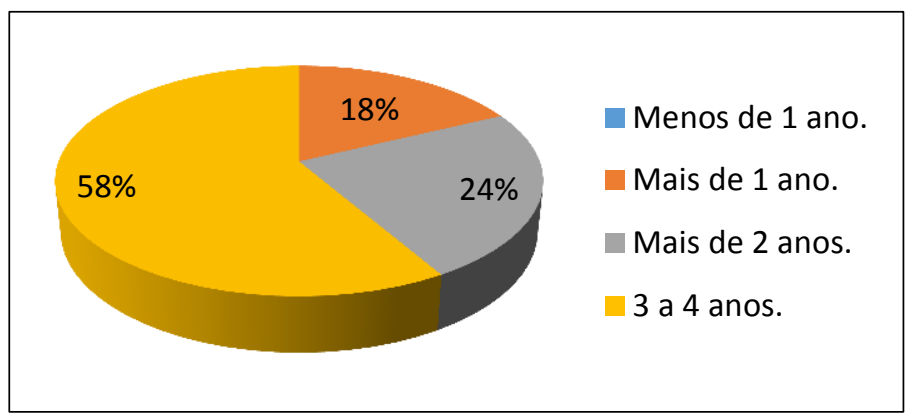

Fonte: elaborados pelos autores

Mais da metade dos entrevistados (58\%), responderam que frequentaram o projeto mais de 3 anos, referindo ao esporte e a convivência com os colegas, $24 \%$ relataram que compareceram ao projeto mais de 2 anos, alguns informaram que trocaram de escola ou foram morar longe, não havendo possibilidades de irem à escola no turno oposto e o restante dos entrevistados (18\%) afirmaram que participaram durante mais de um ano, havendo os mesmos motivos citados anteriormente. Relativamente com o projeto, como mostra o gráfico, podemos destacar que os ex-alunos gostavam das aulas e do esporte, pois praticaram por bastante tempo.

Figura 3: Pergunta 3 - Até hoje você ainda prática tênis?

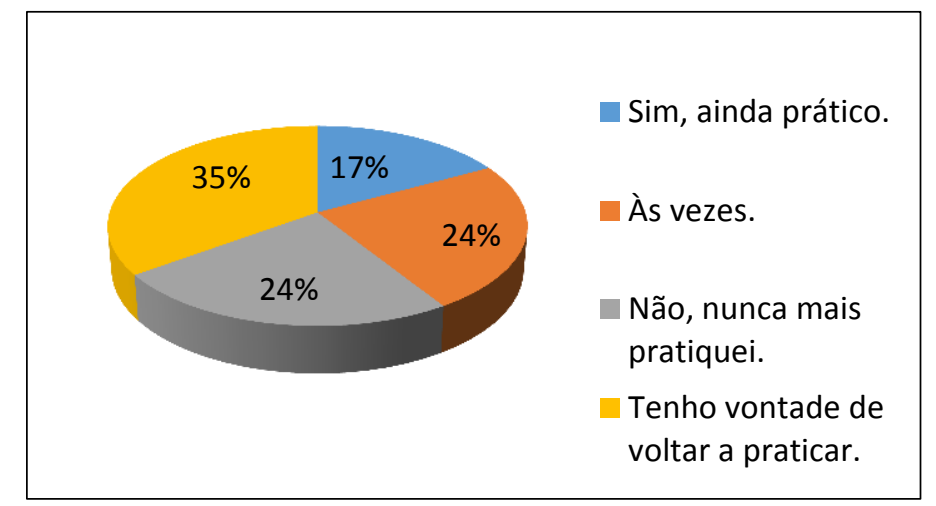

Fonte: elaborados pelos autores

Através do gráfico, verificamos que 35\% dos ex-alunos têm vontade de voltar a praticar tênis, citaram que por falta de interesse no esporte e por preguiça desistiram das aulas e sentem ausência em praticar e de reaprender. $24 \%$ dos entrevistados justificaram que por conta de outros motivos e por estarem trabalhando no horário de aula não podem frequentar as aulas. Outros $24 \%$ ainda praticam o esporte, comparecendo nas aulas quando possível. O restante dos entrevistados, $17 \%$, ainda praticam o esporte nos núcleos do projeto, muitos só estudam e podem frequentar as aulas no turno oposto, de modo que esses alunos são considerados alunos evoluídos. 
Figura 4: Pergunta 4 - Você tinha comprometimento em ir as aulas todos os meses?

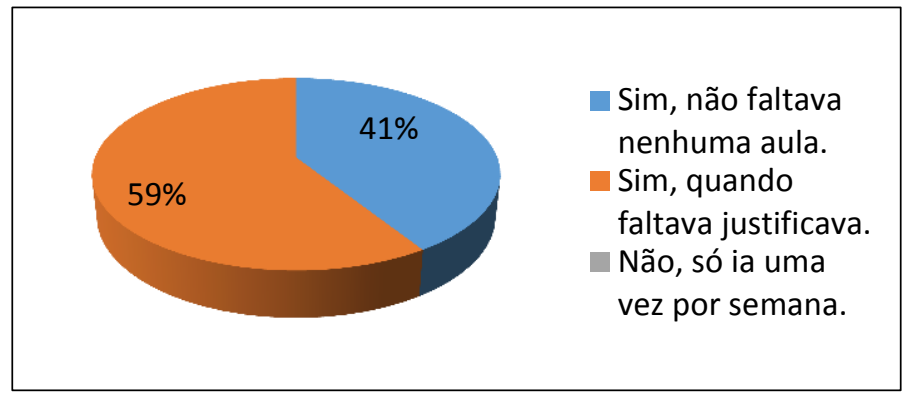

Fonte: elaborados pelos autores

Os dados mostram que $59 \%$ dos entrevistados justificavam suas faltas, resultado do trabalho constante em aula e do comprometimento dos alunos em irem às aulas todos os meses. Os outros $41 \%$ não faltavam nenhuma aula, tendo a participação e responsabilidade de frequentar o projeto. Ponto positivo para os ex-alunos que cumpriam com suas obrigações com o projeto.

Figura 5: Pergunta 5 - Você foi encaminhado para cursos profissionalizantes?

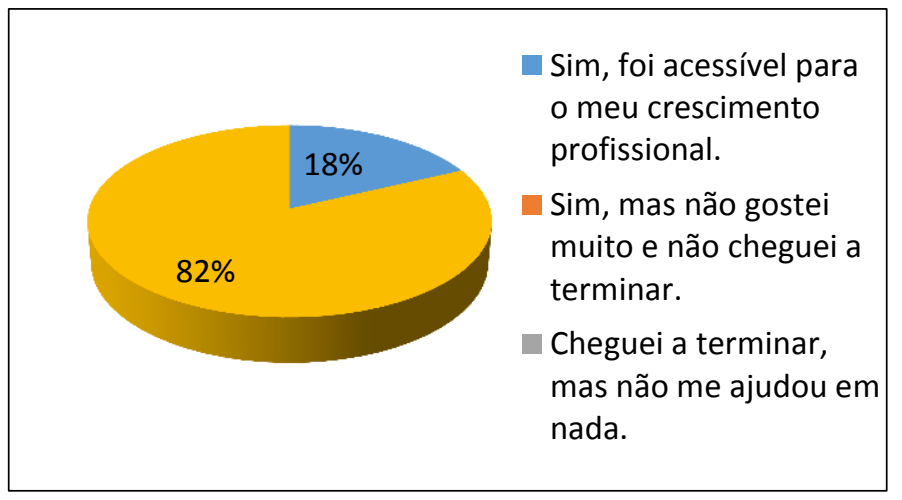

Fonte: elaborados pelos autores

Como exposto no gráfico, a maioria dos entrevistados, no total de $82 \%$, responderam que não foram encaminhados para cursos profissionalizantes, muitos alunos relataram que saíram do projeto antes de serem evoluídos, mas que sabiam dos cursos oferecidos pelo projeto. Mas para $18 \%$ dos entrevistados os cursos profissionalizantes foram oferecidos e foi acessível para o crescimento profissional, podendo estar até hoje no mercado de trabalho. 
Figura 6: Pergunta 6 - Como está sua vida profissional hoje?

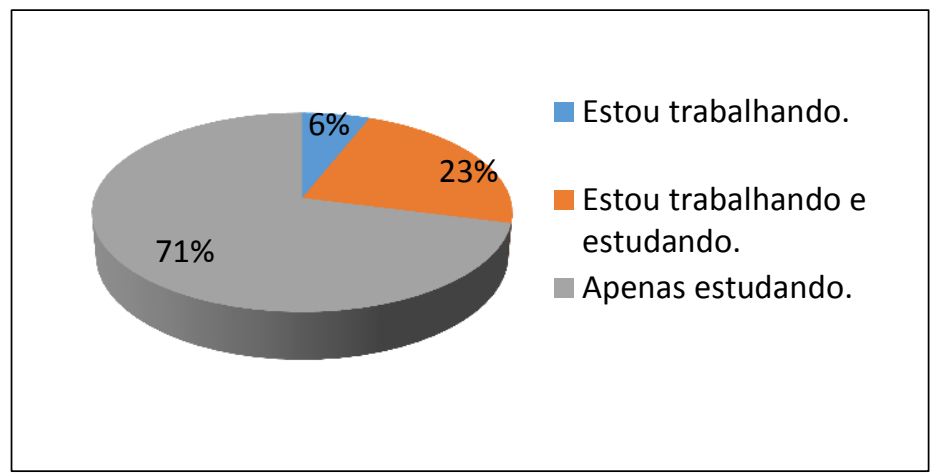

Fonte: elaborados pelos autores

No gráfico, podemos observar que $71 \%$ dos entrevistados apenas estão estudando, muitos já frequentam o ensino superior, apresentando idade entre 16 a 23 anos. Dos ex-alunos, 23\% já estão inseridos no mercado de trabalho, relatando que o projeto contribuiu no crescimento pessoal e profissional e $6 \%$ responderam que o projeto favoreceu sua vida profissional, hoje estando no mercado de trabalho.

O restante das perguntas do questionário constitui-se por 3 perguntas abertas, caracterizadas por serem perguntas livres, nas quais o entrevistado escreve sua opinião sobre as perguntas propostas. São elas:

\section{Os Valores Olímpicos contribuíram no seu crescimento?}

A grande maioria dos entrevistados exemplificou que os valores Olímpicos contribuíram no crescimento dentro e fora das quadras, pois através das aulas os valores nortearam para uma transformação indireta na vida dos alunos, favorecendo a socialização, o respeito dentro das suas casas, na escola e no grupo de amigos. Todos lembram até hoje os três valores aprendidos em aula.

\section{O que fez você entrar no projeto e o que fez deixar? Houve alguma mudança sua depois} que saístes?

Os resultados apresentados nessa resposta indicaram que o motivo de entrarem no projeto é a curiosidade de aprender a jogar tênis, e as razões que fizeram os jovens deixar o projeto foram as oportunidades no mercado de trabalho, a ida para outras escolas por terem concluído o ensino 
fundamental, como afirmado pela minoria e, para outros, foi a falta de transporte até o núcleo do projeto. Sobre as mudanças, eles relatam que saíram com mais responsabilidades, estando no mercado de trabalho.

\section{O que você aprendeu com o projeto e o que ele contribui em sua vida?}

Os resultados dessa questão mostram que, na opinião dos jovens, os valores olímpicos contribuíram na vida de todos fora da escola e que hoje relacionam na convivência em grupos e no trabalho, o que favoreceu no crescimento pessoal e profissional dos ex-alunos entrevistados. Os restantes dos entrevistados responderam que aprenderam a ter convivência em grupo, comprometimento, oportunidades, espírito esportivo, disciplina, responsabilidades e fizeram novas amizades.

\section{Discussão}

A Educação Olímpica pode ser uma ferramenta para oferecer oportunidades e vivências que levam ao crescimento e desenvolvimento social, valor educativo, formação do indivíduo através de uma ação pedagógica na educação. Paralelamente, ao realizar a pesquisa com os ex-alunos do projeto sobre os valores olímpicos notamos que os mesmos relembraram uma fase de suas vidas, em que a maioria dos resultados foram positivos, pois os jovens descrevem a importância dessa aprendizagem, que contribuiu para seu crescimento pessoal e profissional.

Apesar do seu lado elitista, o tênis de quadra não é difundido em muitas escolas (MORTARI, 2016), pois apresentam problemas socioeconômicos ou por falta de interesse docente. Entretanto, notamos que a curiosidade em aprender o tênis fez os entrevistados entrarem para o projeto da Fundação Tênis, corroborando que o aluno, ao entrar no esporte, acaba por ser cativado em aprender, conhecer, tomar gosto pelo novo esporte e, assim, o interesse se torna cada vez maior, pois os desafios estimuladores ampliam a forma como a educação convém na vida dos alunos (PAES, 1996).

Para Balbinotti (2009), o tênis de quadra proporciona muitos benefícios, tanto no aspecto físico quanto no desenvolvimento das habilidades motoras e sociais. Dados da pesquisa mostram que $90 \%$ dos entrevistados responderam que a FT contribuiu na vida dos ex-alunos no comprometimento, na convivência em grupos, disciplinas e responsabilidades, por intermédio da Educação Olímpica, promovendo aspectos relacionados à saúde dos participantes e oportunizando a vivência do tênis de quadra. 
Nota-se que, a cada ano que passa, com o uso da tecnologia, os esportes ficam em segundo plano, ocasionando a falta de habilidade motoras das crianças. Além disso, o número de crianças e jovens sedentários é crescente, com baixa aptidão física e obesos por falta da vida ativa (DARIDO; GALVÃO; FERREIRA; FIORIN, 1999). Porém, ao verificar os resultados, pode-se reconhecer que 59\% dos entrevistados tinham comprometimento em ir às aulas todos os meses, justificando suas faltas e deixando de lado a vida sedentária de não praticar algum esporte.

Um dado revelado por Rocha (2008) mostra que a entrada para o mercado de trabalho dos jovens que apenas estudam, com idade de 18 anos, é inferior quando comparado aos que trabalham e não estudam. Nesse sentido, os dados da pesquisa mostraram que $71 \%$ dos entrevistados apenas estão estudando, esse dado ressalta que há uma dedicação gerada à escola ou à faculdade por esses jovens que apenas estudam, e são poucos jovens que conciliam os estudos com o trabalho. Apenas $6 \%$ dos jovens estão apenas estudando, pois a entrada no mercado de trabalho somado a outros compromissos, fazem com que eles não pratiquem mais a modalidade.

Um ponto negativo encontrado na pesquisa foi relacionado as oportunidades dos participantes de serem inseridos ao mercado de trabalho, onde $18 \%$ dos entrevistados responderam que tiveram oportunidades de realizar cursos profissionalizantes, entretanto poucos tiveram a chance de efetivarem aos cursos oferecidos por circunstâncias desconhecidas, as quais não foram citadas pelos entrevistados, porém os professores ressaltavam em aula a importância da formação desses cursos para a vida dos jovens. Cabe destacar que $82 \%$ dos entrevistados informaram que saíram do projeto antes de serem evoluídos (alunos que concluíram o ensino fundamental em escola municipal), alegando os seguintes motivos: mudança de escola, falta de tempo livre e entrada para o mercado de trabalho.

\section{Considerações finais}

A ideia inicial para a construção desta pesquisa surgiu com a intenção de compreender o projeto FT através do objetivo principal da instituição: possibilitar que os jovens reescrevam seus projetos de vida e tenham condições de se inserir na sociedade como cidadãos, como também, o comprometimento com os objetivos delineados pelo projeto. Dessa forma, os objetivos da pesquisa foram direcionados para a contribuição da Fundação Tênis e dos Valores Olímpicos na vida e na formação escolar de exparticipantes do Projeto nos núcleos de Santiago/RS.

Através da pesquisa, verificou-se que o real motivo que levou os ex-alunos a frequentar as aulas do projeto foi a curiosidade em aprender a jogar tênis e que, para a maioria, o esporte era uma grande 
novidade por ser pouco trabalhado em escolas. Os resultados mostram que os professores tinham um papel importante na educação desses jovens, pois através do esporte eles transmitiram conhecimentos e acrescentaram valores no crescimento tanto pessoal como profissional. Cabe salientar que os valores olímpicos trabalhados em aula contribuíram na vida da maioria dos entrevistados, sendo de total importância para eles no crescimento dentro do projeto e consequentemente na formação fora dele.

Notamos que a excelência diária, requisito obrigatório dos integrantes do projeto através do respeito com os colegas, professores e materiais; inclui o fair play, favoreceu na socialização do aluno, somado à aprendizagem através do cumprimento das tarefas e das atividades.

Relacionado ao encaminhamento para os cursos, os participantes foram encaminhados para cursos profissionalizantes, podendo trabalhar em empresas na cidade, o que foi de grande crescimento profissional. Além disso, os participantes tiveram oportunidades de aprender, de conhecer, de vivenciar o esporte, de ingressarem no mercado de trabalho e terem competências apreendidas em aula, entretanto, esses ensinamentos foram realçados fora do projeto, e em suas vidas.

Percebemos que a escola se caracteriza como um fator primordial para o projeto, pois através dela pode-se conhecer e descrever a realidade de cada estudante, auxiliando na busca de soluções de problemas encontrados. Assim, os vínculos com a comunidade escolar através de professores e psicólogos permitem aproximar o que acontece dentro da sala de aula e em quadra.

Como sugestões para que o projeto seja melhorado, propomos que os cursos sejam oferecidos para todos os alunos que fazem parte do projeto, com idade entre 13 a 16 anos, para que futuramente sejam encaminhados para o mercado de trabalho, tendo o auxílio de um curso preparatório oferecido pelo projeto. Sugere-se também proporcionar encontros a esses alunos com os empresários da cidade, para incentivar o seu primeiro emprego e para trocas de ideias, para que aprendam a como se integrar no ambiente de trabalho. Além disso, para aqueles alunos que estão por encerar o ensino fundamental, deve haver um acompanhamento dos monitores para não desistirem do projeto e para estarem preparados para o seu primeiro emprego, podendo conciliar os estudos com o trabalho.

Direcionado aos professores, acreditamos que os mesmos devem utilizar a Educação Olímpica como uma ferramenta a favor do ensino dos esportes, auxílio e prevenção da saúde, desenvolvimento físico, cognitivo e social dos alunos, proporcionando experiências e oportunidades, além de utilizarem como exemplos os alunos mais antigos e que obtiveram êxito nesse objetivo. 


\section{Referências}

ALEXANDER, K.; LUCKMAN, J. Australian Teacher's Perceptions and Uses of the Sport Education Curriculum Model. European Physical Education Review, Driffield, v. 7, p. 243-267, 2001.

BALBINOTTI, C et al. O ensino do tênis: novas perspectivas de aprendizagem. Porto Alegre: Artmed, 2009.

CERVO, A. L.; BERVIAN, P. A. Metodologia cientifica. 5. Ed. São Paulo: Prentice Hall, 2002.

COUBERTIN, P. Olympic Letter V. Olympic Pedagogy, (1918). In: Müller, N. (ed): Olympism. Selected Writings of Pierre de Coubertin. Lausanne, IOC, p.217. 2000.

DAIUTO, M. Metodologia do ensino: basquetebol. São Paulo: Brasipal,1983.

DARIDO, S. C.; GALVÃO, Z.; FERREIRA, L. A.; FIORIN, G. Educação física no ensino médio: reflexões e ações. Motriz. 1999.

FLICK, U. Introdução à Pesquisa Qualitativa - 3.ed. 2008. ISBN 9788536318523. Disponível em: <https://books.google.com.br/books?id=dKmqDAAAQBAJ>.

GRAÇA, A. B. S. O desporto na escola: enquadramento da pratica. In: GAYA, A.; MARQUES, A.; TANI, G. (Eds.). Desporto para crianças e jovens. Razões e Finalidades. Porto Alegre: UFGRS, 2004. P. 97-112.

MARINS, A.G.; DOS SANTOS, A. F.; MARQUES, J. H. O Olimpismo como Estratégia para a Produção e Conservação da Hegemonia. Revista Brasileira de Ciências do Esporte, Florianópolis, v. 36, n. 2, supl., p. S428-S440, abr./jun. 2014.

MORTARI, A. J. Tênis de campo: da aplicação prática a uma proposta de inserção na educação física escolar. Artigo de conclusão de curso da Universidade Federal de Santa Maria (UFSM, RS) 2016.

MÜllER, N./IOC (eds): Pierre de Coubertin. Texteschoisis. Vol.II « Olympisme ». Zurich, Hildesheim, New York, p.418.1986.

PARA O DESENVOlVIMENTO, ONU Esporte. A Paz: Em Direção à Realização da Metas de Desenvolvimento do Milênio. 2003. 2007.

PAES, R. R. O esporte como conteúdo pedagógico do ensino fundamental. Campinas, 1996. Tese (Doutorado) - Faculdade de Educação, UNICAMP, 1996. p. 75

PINTO, J.A.; CUNHA, F. H. G. O tênis como alternativa no currículo escolar para crianças entre 8 e 12 anos. Motriz, v.4, n. 1, jun. 1998.

PINTO, L. M. M.; RODRIGUES, R. P.; ENGELMAN, S. Olimpismo e educação olímpica no Brasil. Porto Alegre: Editora da UFRGS, 2009.

PRODANOV, C. C.; DE FREITAS, E. C. Metodologia do Trabalho Científico: Métodos e Técnicas da Pesquisa e do Trabalho Acadêmico-2a Edição. Editora Feevale, 2013. ISBN 8577171582. 
ROCHA, S. A inserção dos jovens no mercado de trabalho. Caderno CRH, v. 21, n. 54, 2008.

TAVARES, O. Esporte, movimento olímpico e democracia: o atleta como mediador. Tese de doutorado. Programa de Pós-Graduação em Educação Física. Universidade Gama Filho. Rio de Janeiro, 2003.

TODT, N. S.O Futuro dos Megaeventos Esportivos. Inovações Pós Copa 2014 e Jogos Olímpicos e Paralímpicos 2016. Programas de Educação Olímpica Reconhecidos Pelo Comitê Brasileiro Pierre de Coubertin: Um Modelo Renovador de Parcerias Tomando Forma no Brasi. Editora FAPERJ. Brasil, Rio de Janeiro. 2015.

TODT, N. S. Um país Olímpico sem Educação Olímpica? - a construção de um legado real. 2014. (Apresentação de Trabalho/Conferência ou palestra). Acesso em: 26 Março. 2017.

\section{Como citar este artigo}

ROSA, A. S.; LAPORTA, L. I.. A contribuição da fundação tênis e dos valores olímpicos na vida e na formação escolar de ex-participantes do projeto em Santiago/RS. Revista Kinesis, Santa Maria, v. 38, p. 01-14, 2020.

* O presente trabalho não contou com apoio financeiro de nenhuma natureza para sua realização. 